\title{
Requisite leader behavioural competencies for sustainable organisational performance
}

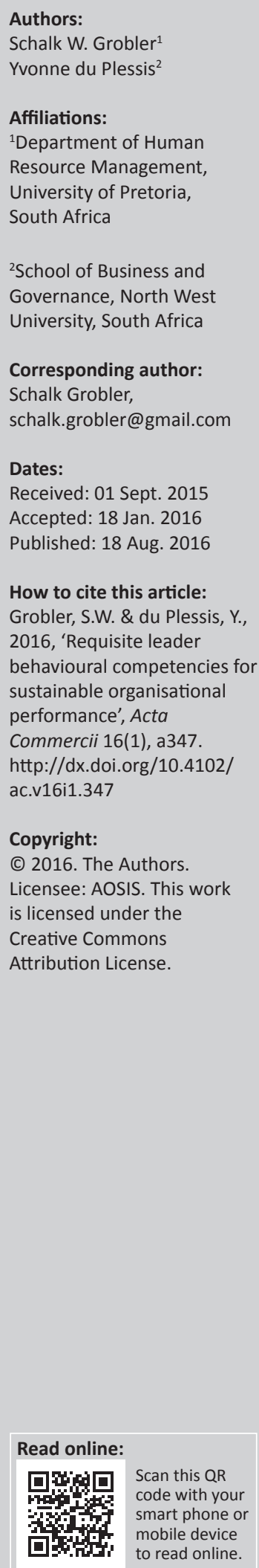

Orientation: Organisations constantly strive to understand the impact of leader behaviour on continued superior organisational performance.

Research purpose: The purpose of the study was to establish a framework of requisite leader behavioural competencies for sustainable (repeated) organisational performance and to determine the interrelationship between leader behaviour and sustainable organisational performance.

Rationale/ motivation: Many studies have been conducted investigating the impact of leadership on organisational performance, but a gap exists in studying the interplay between leader behavioural competencies, organisational performance and organisational context.

Research design, approach and method: A case study research design was used employing a qualitative approach with a constructivist grounded theory research philosophy. Data collection comprised archival document review and semi-structured, in-depth interviews with senior executives in a high performing multinational listed South African organisation as case. Data analysis was conducted with the aid of qualitative data analysis computer software, as well as through iterative open and axial coding to discover patterns and themes.

Main findings: The study resulted in a leader behavioural competency framework purporting a model founded strongly in context and simplicity.

Practical/ Managerial implications: Requisite leader behavioural competencies were identified as: 1) simple focus and providing direction; 2) a sincere regard for people, or employee wellbeing; 3) creating an environment of absolute trust and empowerment; 4) enforcing innovation and entrepreneurship; 5) full leader support and backup; and 6) affording profound reward and recognition for achievements.

Contribution: Organisations can benefit from an insight into understanding how the identified requisite leader behavioural competencies possibly can impact organisational performance in their respective environments.

\section{Introduction}

Successful organisations are effective at articulating, communicating, and implementing performance concepts, building meaningful relationships, and measuring results (Simon 1998). Organisational performance analysis is typically carried out at the individual, programme, and organisational level; however, the relationship between individual effectiveness and organisational performance, based on measurable outcomes, remains elusive (Brewer, Selden \& Facer 2000). Management literature, further, frequently reminds us that people (human capital) are the most important resource with which to enable superior performance (Pfeffer 1994; Rainey 1997).

Competence models are a means of facilitating organisational values and strategic organisational objectives. However, minimum standards in terms of behavioural competence may not necessarily be sufficient, nor is it clear what differentiates effective leaders from excellent leaders. Most organisations aspire to leadership excellence, and therefore wish to identify and clarify these competencies (Hollenbeck, McCall \& Silzer 2006).

Organisations often enhance employees' technical competencies to increase performance, in order to achieve organisational objectives (Miller, Rankin \& Neathey 2001); however, utilising competencies for both assessment and development may negatively impact on the effectiveness of increased competencies as a development tool (Conger 2005). 
The main problem is that many organisations fail to sustain their performance, and become obsolete, with resultant deficits and socio-economic implications. A study by Ogbonna and Harris (2000) confirmed the causal links between organisational culture, leader behaviour, and organisational performance, but the relationship between leader behaviour and outcomes, such as sustained superior organisational performance, remain under-researched and is not adequately described in the literature.

The organisation under study seems to have mastered enabling sustainable performance during difficult times and over decades. As leadership plays a key role in organisational performance, the study set out to research the requisite leader behavioural competencies, linking outcomes of behaviour to sustainable organisational performance, as this has not been researched. This could add value to the existing body of knowledge by expanding on leader behavioural competencies and sustained superior organisational performance.

A conceptual framework clarifying the contextual leader behaviours necessary for sustainable organisational performance can enable strategic organisational alignment (the process of linking organisational outcomes and activities with the vision, goals, objectives, and strategy of the organisation) and greatly enhance long-term organisational success, clarifying the 'soft side' of strategy (the often intangible, behavioural skills, including people management and interaction skills) by identifying desired organisational outcomes as a starting point, as opposed to the end goal.

\section{Research methodology and design}

A case study research design with multiple sub-cases (Yin 2009) was employed, and probed the responses from top executives in a particular high-performing South African organisation, to collect and compare evidence of requisite leader behaviours for sustainable organisational performance. The organisation studied was mainly selected because of its ability to consistently achieve double-digit growth over an extended period of time, and is regarded a South African success story, having been referred to as 'Africa's closest comparator to General Electric' (Forbes 2012:43).

A qualitative approach, with a constructivist grounded theory research philosophy, was utilised during the execution of the study. When exploring the answers to questions 'What?', 'How?' and 'Why?', case study research design is deemed appropriate. Constructivism formed the basis for the research philosophy framework (Creswell 2009), and grounded theory guided the overarching data collection methodology (Charmaz 2006; Guba \& Lincoln 1998; Strauss \& Corbin 1998), with the aim of building theory through an inductive approach. It is acknowledged that theory built from a qualitative case study may not be generalisable, and may require further testing.

A meso-level paradigm has been applied to understand the macro-level phenomena (represented by the organisational philosophy) and micro-level phenomena (represented by individual leader behaviours). In understanding meso theory, the impact of the context on behaviour was considered, as well as the manner in which context was understood and constructed by the individual (Rousseau \& House 1994).

The study focused on organisational behaviour from an organisational and an individual perspective. At macro-level, there are a number of external factors which could have impacted on behaviour, for example, legal and regulatory factors, the economic climate, and external stakeholders. Internally, or at micro-level, organisational culture, leadership and organisational values could have greatly influenced behaviour.

Data collection comprised of an archival document review, and semi-structured, in-depth interviews with seven senior executive leaders in the organisation, with an extant literature review after data collection and analysis. The process of data collection was conducted in six main phases:

- An initial online documentary and archival group records review.

- Conducting the interviews.

- Transcription of the interviews.

- Validation and anonymising of the transcripts.

- Coding of the data with the aid of a ATLAS.ti®.

- A post-primary data collection (interviews) online review of documentary and archival group records.

The data analysis process was conducted with the aid of qualitative data analysis computer software (ATLAS.ti®) through iterative open and axial coding to discover patterns and themes, and was coupled with the constant comparison and triangulation of data.

The actual coding process consisted of making notes on printed documents, and drawing up handwritten categories and maps, which were then transferred to ATLAS.ti ${ }^{\circledR}$ once core categories started emerging.

Glaser (1992:38) defined coding as '... the conceptualisation of data by the constant comparison of incident with incident, and incident with concept, in order to develop categories and their properties.' The iterative coding process therefore moves through various levels of abstraction to arrive at an underlying framework. In the study, coding started with open coding, and progressed through several layers of abstraction to achieve axial and selective coding.

Figure 1 depicts the iterative process of coding to move from open coding to eventual family categorisation.

\section{Research rigour}

Guba and Lincoln (1998) proposed alternative terms to address the reliability and validity in qualitative research, and introduced the terms credibility, dependability, confirmability, and transferability when discussing the trustworthiness of qualitative research. 


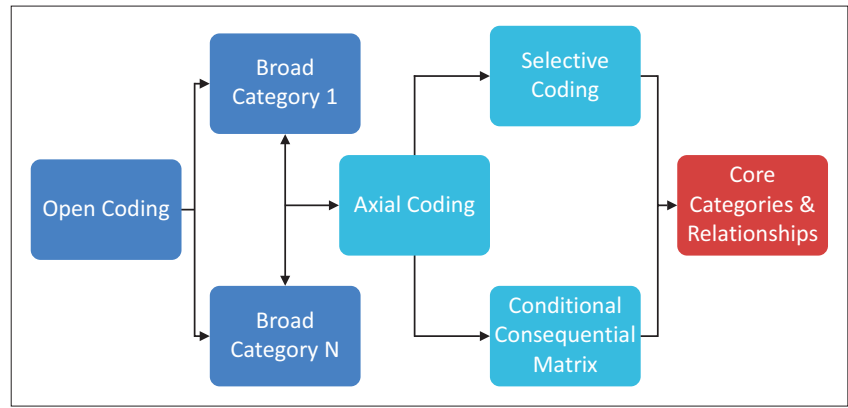

Source: Burden and Roodt 2007

FIGURE 1: Iterative coding process.

Credibility is assessed through the correlation of findings with actual reality. In the research, the data collected from documents, records, and interviews provided a comprehensive reflection of reality through the process of triangulation. The use of multiple sources of evidence was an important way of ensuring credibility and transferability in qualitative and, more specifically, case study research (Guba \& Lincoln 1998; Shah \& Corley 2006; Yin 2009).

Dependability entails the replication of outcomes under similar circumstances. To promote the dependability of the study, all processes have been documented, databases have been maintained, and the use of computer-aided software programs, in this instance ATLAS.ti ${ }^{\circledR}$, provided additional transparency regarding data analysis and findings (Guba \& Lincoln 1982; Shah \& Corley 2006).

Confirmability is concerned with the objectivity of research and results (Guba \& Lincoln 1982). In the case of an insider researcher, the subjectivity of the researcher contributes to the findings of the study. Transparency regarding the research philosophy and perspectives is therefore important. In the study, data were recorded and managed carefully, transcripts of interviews, and memos were kept, and have been stored electronically to allow readers access to the raw data and the documented process of analysis and coding. Data analysis was conducted with computeraided software, to ensure research rigour and objectivity. Field notes were used, and the researcher was constantly aware of and guarded against possible subjectivity; however, possible shortcomings in the methodology were recognised.

Transferability refers to the generalisability of findings; therefore, a multiple case study approach has been followed in the study to enhance transferability. Transferability refers to the generalisability or universalisation of results (Guba \& Lincoln 1982; Yin 2009).

The case-study approach applied in the study, with multiple sub-cases, enabled the cross-referencing of findings, and established possible commonalities and differences, and therefore enhanced research rigour and addressed requirements of credibility, dependability, confirmability, and transferability (Guba \& Lincoln 1998).

\section{Ethical considerations}

Research involving human beings should consider the ethical implications of the study. This includes the research methodology, which should be morally acceptable to the people involved. Gaining access to participants, collecting and analysing gathered data, and reporting findings should be carried out in a moral and responsible way, and not do any harm to anyone involved throughout the process (Mouton 2001).

Prior to interviewing any of the participants, consent was obtained from the organisation studied, as well as from the participants individually. The nature and purpose of the research was explained to the participants, and it was explained that their participation in the research was entirely voluntary, and that they could withdraw at any point during the interview. During the research process it was explained that:

- Participants' names, identities, the name of the organisation, and their responses and comments would not be disclosed, and would be treated as confidential.

- No organisational or industry-related information would be disclosed.

- Interviews would be recorded.

- The participants would have access to the study's results and findings upon request.

All the participants agreed and signed the letter of consent prior to interviews commencing. Informed consent is defined as '... the voluntary and revocable agreement of a competent individual to participate in the research procedure, based on an adequate understanding of its nature, purpose and implications' (Leedy \& Ormrod 2005:101).

Participants were also informed that data collected during the research would be treated confidentially, and that it would only be used for academic purposes.

\section{Results, findings and interpretation}

Yukl (1998) defined leadership as a process through which individuals within a group or organisation influence events, select goals and strategies, and encourage people to achieve objectives, whilst enlisting support from outside the organisation.

Establishing a cohesive organisational identity to which individual organisational members can subscribe and follow has been purported to be the primary goal of leadership (Ackerman 2000; Collins \& Porras 1996). The culture of an organisation is established by the core values and beliefs that drive organisational behaviour, and is primarily formed by top leaders' behaviour, which constitutes the organisational identity. Organisational identity affects how people in the organisation interpret and react to issues, communicate, and behave, answering the question, 'Who are we?' (Foreman \& Whetten 2002). 
From the case study, it emerged that the creation of a strong and unified organisational identity seems to be a key driver of organisational success, although it may not necessarily be deliberately proclaimed. Deep-seated beliefs and how these are enacted within the organisation create a core, shared philosophy that drives organisational performance: the common understanding of 'the way we do things around here.' This was highlighted in the organisation under study by the shared belief in simplicity, both organisational and individual, coupled with a sense of absolute trust and empowerment, reinforced by its decentralised organisational design.

Being truly decentralised, independence, coupled with an overarching agreed financial revenue target, essentially forces innovation within each company or business unit. Leaders are expected, with a keen understanding of their own businesses, markets, and environments to find unique and novel ways to meet their targets.

The decentralised model is coupled with deep levels of trust, but also high levels of accountability, and although such independence is endorsed, this is not carried out without genuine and sincere motivation, enablement, and support of people: 'We've got your back' (P4).

The importance of leader style or behaviour, as well as organisational culture's impact on organisational performance, has been established in literature, and the role of leaders in creating or maintaining the organisational culture has been recognised (Denison 1990; Howell \& Avolio 1993; Schein 1992). When an organisation is formed, a culture emerges, which reflects the founder's values and beliefs (Schein 1992). The observations from the case study reinforce this view, as a strong, common understanding of 'our way' was evident, and was shared amongst participants.

A primary objective of the study was to determine the interplay between leader behaviour and sustainable organisational performance. The initial objective was not to include or investigate the impact of culture on leader behaviour and sustainable organisational performance; however, upon data analysis and the extant literature review, the impact and influence of context and culture emerged as a significant contributor to leader behaviour and sustainable organisational performance (in the study, coded as the 'Organisational Philosophy' core family), as postulated in the literature (Hennessey 1998; Ogbonna \& Harris 2000).

The interplay between organisational performance drivers, the organisational philosophy/cultural identity, and leader behaviour is illustrated in Figure 2.

Organisational culture was described by Ogbonna and Harris (2000) as having a mediating effect on the relationship between leader behaviour and organisational performance, as depicted in Figure 3.

It can therefore be postulated that organisational culture (organisational philosophy) not only plays an interceding role between leader behaviour and organisational performance, but, perhaps more importantly, an enabling role: what the organisation values determines the actions of its members, which, when continuously repeated, entrenches these behaviours. These behaviours, in turn, shape and reinforce the culture of the organisation, answering the question, 'Who are we?'

The enabling role of organisational context in the interplay between leader behaviour and organisational performance is diagrammatically depicted in Figure 4.

The impact of the organisational context on observable leader behavioural competence again emerged from this study. The organisation studied, however, did not have, and almost seemed to shy away from, a formal and structured leadership model or formal structures to enable or replicate this, nor did it proclaim a specific culture, future vision, or models to which management should subscribe. 'The way we do things around here' is inculcated in the organisational ethos, and is made even more powerful by its implicit and embedded nature, as opposed to overt and grandiose templates or models.

In one 2014 corporate communication bulletin, the following statement was made by the group's chief executive officer (CEO):

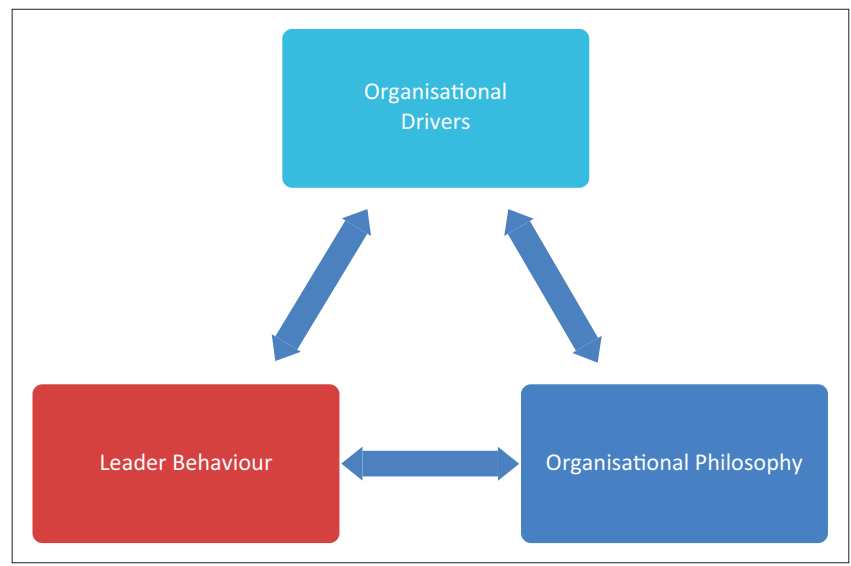

Source: Grobler 2015

FIGURE 2: Interplay between organisational performance, organisational philosophy and leader behaviour.

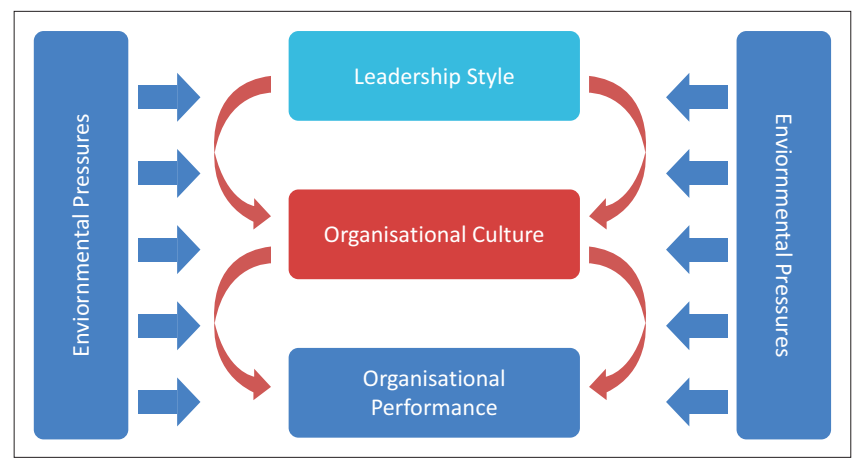

Source: Adapted from Ogbonna and Harris (2000)

FIGURE 3: Organisational culture and the effect on leader behaviours and organisational performance. 


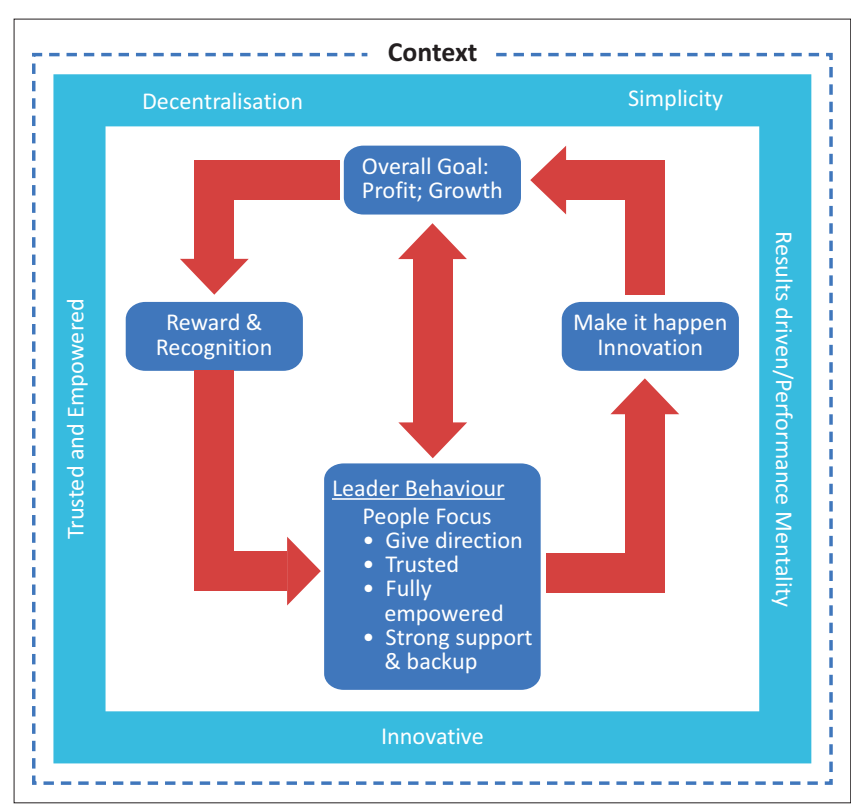

Source: Grobler 2015

FIGURE 4: Influence of organisational context on leader behaviour

When growth like this occurs at other companies the analysts talk about a 'period of consolidation.' Months and years go by while the organisational charts are redrawn and the newcomers are handed their standardised operating procedures and begin to relearn their business. This doesn't happen at [the group]. Sure, we consolidate and integrate, but we don't impose a single [the group] template.

The above is further emphasised by the organisation's insistence on simplicity, which was mentioned a number of times during various interviews with reference to the setting of goals and targets, the measurement of performance, the organisational structure, the management hierarchy, and organisational philosophy, evidenced by its leaders' behaviours.

\section{Discussion}

\section{Towards a conceptual leader behavioural competency framework}

The objectives of the research were to develop a framework of requisite leader behavioural competencies that enable sustainable organisational performance, analyse the measures of sustainable organisational performance, and investigate the interplay between leader behavioural competence and sustainable organisational performance.

Such a conceptual framework (clarifying the contextual leader behavioural competencies necessary for sustainable organisational performance), if applied, can enable strategic organisational alignment and enhance long-term organisational success and sustainability.

Identifying desired organisational outcomes as a starting point (organisational performance outcomes), as opposed to these being the end goal, can provide insight into the soft side of strategy, the often less tangible behaviours that drive an organisation's members.

\section{The impact of context and culture on leader behaviour and organisational performance}

Moving towards a framework of requisite leader behaviour for sustainable high performance, it was established that the larger context of the organisation that emerged from the study cannot be ignored, which is supported by the study of Harris and Ogbonna (1999). Contextual or environmental factors and, most notably, organisational culture were established to have a significant impact in moderating the interplay between leader behaviour and organisational performance (Harris \& Ogbonna 1999).

Leaders play an instrumental role in organisational success, directly impact on organisational performance, and influence the climate for sustained organisational performance, basically setting the tone for the overall organisational identity or philosophy (Bass 1990).

This strong interaction between leader behaviour and organisational philosophy (the one drives the other) was again confirmed by the study, in which it was found that the organisational structure of true decentralisation (and subsequent high levels of trust and empowerment), coupled with an organisational philosophy of simplicity (in goalsetting, performance measurement, reward and recognition, reciprocal support, etc.), shapes and drives leader behaviour. This, in turn, entrenches the organisational philosophy or culture, again by virtue of its leaders' enactment of these shared beliefs and understanding of 'the way we are.'

During the analysis of data, and based on the coding process with the aid of ATLAS.ti ${ }^{\circledR}$, a pattern started evolving indicating that the key organisational drivers of performance are supported by a rather distinct, although not necessarily overt or explicit, organisational philosophy, or 'the way we do things'. The clear and objective overarching goal in the organisation studied creates and reinforces a commonly understood organisational philosophy or culture, which, in turn, impacts and determines the way in which its leaders behave. These leader behaviours (providing direction, trusting and empowering subordinates, displaying a genuine regard for the well-being of subordinates, appropriately rewarding and recognising subordinates' efforts and achievements, and truly backing up and supporting subordinates) in turn confirm and strengthen the organisation's philosophies around keeping things simple, decentralisation, trusting and empowering its leaders, and creating a performance- and results-driven mentality, which culminates in the organisation repeatedly meeting its profit and growth targets. The profit and growth (sustainability) drivers provide a starting point for creating a perpetual cycle.

This perpetual cycle of influence between organisational drivers, organisational philosophy, and leader behaviours is diagrammatically depicted in Figure 5.

Although the literature suggests that the active changing of an organisation's culture may have a positive impact on 


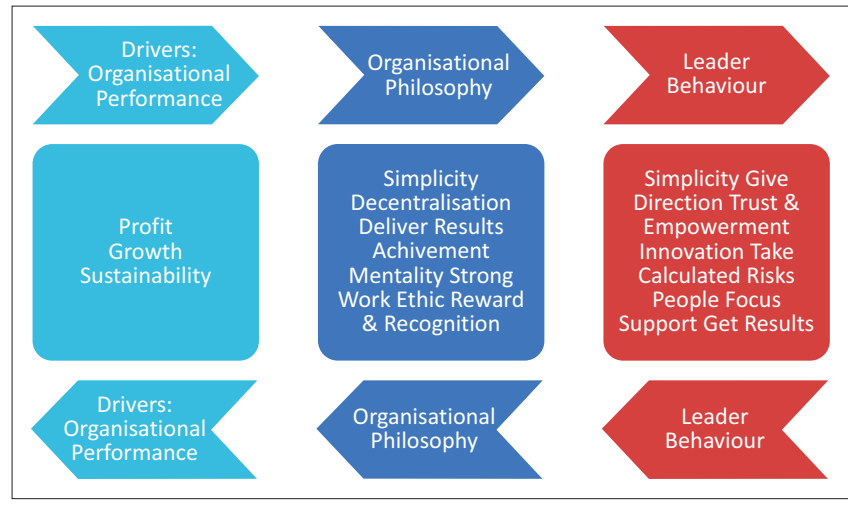

Source: Grobler 2015

FIGURE 5: Perpetual cycle of influence between organisational drivers, organisational philosophy, and leader behaviours.

effectiveness and efficiency (Kotter \& Heskett 1992), it was apparent in the organisation studied that the group does not wish or attempt to manage or change its culture in any way. Rather, the organisational culture is regarded as its unique differentiator, relayed with a profound sense of pride. This was, upon reflection, evident in the top leaders' initial reluctance to discuss the group's culture.

The cyclical combination of intent, philosophy, and behaviour, becomes the self-sustaining pattern of thinking and behaving within the organisation that compels its repeated high performance.

From an organisational behaviour perspective this cyclical process reinforces the view that behaviour impacts on the organisational, group, and individual levels, as demonstrated by the reciprocal impact of leader behaviour on the organisation, and the organisational context on leader behaviour.

\section{Simplicity as organisational ethos}

Organisational behaviour theory can be examined in terms of the behaviour of the organisation (macro-level), the behaviour of groups in the organisation (meso-level), and the behaviour of individuals in the organisation (micro-level) (Wagner \& Hollenbeck 2010). In the study, simplicity was identified as a key phenomenon within the organisation, and, when extrapolated in line with organisational behaviour theory, the following was revealed in terms of its application.

Firstly, simplicity is evident in terms of the organisation's organisational philosophy (macro-level), its core business model and overarching reason for existence, namely, to make money and to grow.

Simplicity is further applied in terms of group business performance management and execution, and the behaviour of the collective in the organisation (meso-level), evident in a decentralised business model, with leadership being absolutely trusted and empowered to realise the overarching organisational philosophy.
Lastly, simplicity was proposed by the participants as an inherent individual characteristic of both the group's founder and group CEO and of the top leaders in the organisation (micro-level). For example, when prompted to identify the characteristics of a leader in the organisation under study, the following responses were amongst those provided in the interviews:

'[S]omeone who is clear, simple...' (P4).

'[S]ome of the characteristics we do have across the group: the guys are quite simple...' (P5).

' $[Y]$ ou want a guy who is a simple oke, who tells it as it is, and that everybody can understand...' (P1).

'[I]t is important that he is a simple guy...' (P4).

The following was stated with regard to the founder and CEO, specifically:

'[T] he type of guy who anybody could talk to ... who is quite a simple person...' (P4).

Simplicity at the macro-, meso- and micro-level is diagrammatically depicted in Figure 6.

The study resulted in a leader behavioural competency framework, founded strongly in simplicity with reference to a clear and objective, common overarching organisational goal and 'reason for existence'; in this instance, an overt and unashamedly declared profit motive. Simplicity is further found in the organisation's operational business management and execution; it wishes not to unnecessarily overcomplicate and burden the process of 'doing business.' Simplicity, lastly, is stated and advocated as an individual leadership quality, and leaders are not purported to be exceedingly important or venerable; as expressed by the CEO of one of the divisions of the company under study: 'We are actually quite simple people.'

\section{Decentralisation, absolute trust and empowerment}

A further profound finding was the organisation's truly decentralised organisational structure and execution model: its business leaders have full authority to act, and are held accountable. They enjoy absolute trust and empowerment, thereby not only being allowed to 'make it happen,' but compelling entrepreneurship and innovation within the organisation.

The singular overarching goal of making a profit within the context of total decentralisation and absolute trust and empowerment is further evident in the organisation's seeming lack of detailed organisational leadership or business models. Its power to continuously financially perform well and grow rather resides in the implicit organisational philosophy of 'doing it' rather than merely 'saying it.'

The conceptual theoretical framework developed in the study indicates the possible interplay between leaders' 


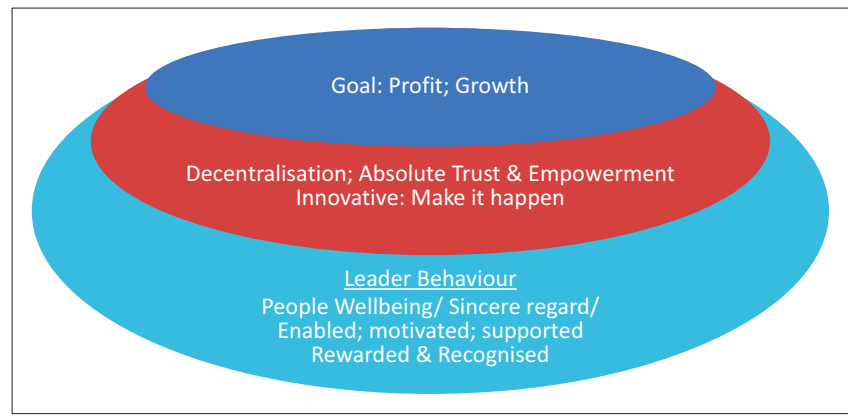

Source: Grobler 2015

FIGURE 6: Simplicity of the group's philosophy on the macro-, meso-, and microlevel.

behavioural competencies, organisational context or culture, and sustainable high performance. The study expanded the existing theory of leader behavioural competence by integrating and incorporating organisational behaviour theory to further understand the role and importance of, especially, executive leader behaviour in organisational outcomes and sustainable performance.

\section{Leader behavioural competencies}

The six requisite leader behavioural competencies that result in sustainable organisational performance in a highly competitive business environment were identified as:

- A simple focus and providing direction.

- A sincere regard for people and employee well-being.

- Creating an environment of absolute trust and empowerment.

- Enforcing innovation and entrepreneurship.

- Full leader support and backup.

- Generous reward and recognition for achievements.

Organisations can benefit from insight into how the identified requisite leader behavioural competencies can and do impact organisational performance. Such insight can further assist organisations to adapt or incorporate the findings of this study in their requirements regarding leader behaviour, to facilitate sustainable success.

\section{Limitations of the study}

This study has certain limitations that should be recognised.

Although a case-study approach, with multiple sub-cases, was followed to enhance the credibility, dependability and transferability of the findings, the study was cross-sectional. Further, the use of interviewing as the only method of collecting primary data, especially in a cross-sectional approach, has received criticism; behavioural manifestations are purported to be different under different circumstances, for example, in less than ideal or crisis situations, compared to ideal circumstances. Therefore, a longitudinal study may have augmented the insights of the study as recommended by Parry (1998).

A larger research sample may have increased the credibility and trustworthiness of the findings, although data saturation was reached at an early stage during the qualitative data collection process.

The applicability of results and findings to other contexts and countries may be limited (Mouton 2001).

The study focused on observable leader behaviour, and did not include the drivers of behaviour, for example, traits or personality characteristics.

The absence of organisational frameworks or models, including a leader behaviour competence framework, may work well at the top echelons of the organisation, but the study did not consider whether this would deliver the same results in other parts of or throughout an organisation.

The longevity and overall sustainability of the business philosophy could perhaps be questioned. One participant in particular, during an interview, also raised doubts in this regard: ' $[H]$ owever long they can continue to sustain that...?' (P2).

Markets and business environments are constantly changing and becoming more complex, and macro-events, such as the USA's financial crisis of 2008 and 2009, may have a severely negative impact on, especially, revenue and growth.

\section{Opportunities for future research}

The study highlighted the multidimensional and complex nature of leadership and leader behaviour in a highperforming business environment. Possible opportunities for further research, from this study, in the spheres of leader behaviour, sustainable organisational performance, and organisational culture or philosophy are provided below.

Although qualitative research has distinct advantages over quantitative methods when investigating complex, multidimensional, and contextual social phenomena, such as leader behaviour (Bryman 2012; Bryman, Stephens \& Campo 1996; Conger \& Kanungo 1998), it is still underutilised as a research method. It is evident from this study that qualitative studies in the field of leader behaviour can contribute to the existing body of knowledge and it is suggested that more qualitative studies be conducted on leader behaviour and organisational performance within different organisational contexts.

A deeper examination of the underlying causal mechanisms, using, for example, structural equation modelling, could prove useful in further clarifying the relationship between leader behaviour and organisational performance by evaluating the framework developed in this study in various business contexts.

Empirical testing of the conceptual framework depicted in Figure 4 in order to develop a leadership scale or instrument could be used to measure leader behavioural competencies for sustainable organisational performance - the conceptual framework depicted in Figure 4 could be tested quantitatively. 


\section{Conclusion}

In the study, the development of a leader behaviour competence framework seems to have led to a dichotomy: on the one hand, the main aim of the study was to develop and define a leader behaviour competence framework for sustainable high performance, whilst the studied organisation's success seemed to, paradoxically, reside in its near-deliberate insistence on not overtly defining, describing, or prescribing any organisational models or frameworks for leader behaviours that support success. However, the group simultaneously cultivates a deep sense of what exactly is required of its leaders - the inculcation of the fundamental and long-standing organisational principles and beliefs.

Perhaps Occam's razor, as described by Swinburne, best describes the group's ethos:

The simplest hypothesis proposed as an explanation of phenomena is more likely to be the true one than is any other available hypothesis, that its predictions are more likely to be true than those of any other available hypothesis, and that it is an ultimate a priori epistemic principle that simplicity is evidence for truth (Swinburne 1997:1),

\section{Acknowledgements Competing interests}

The authors declare that they have no financial or personal relationships which may have inappropriately influenced them in writing this article.

\section{Authors' contributions}

S.W.G conducted the research as part of the completion of his $\mathrm{PhD}$. Y.d.P. provided overall guidance, input and supervision throughout the research project, and finally approved the manuscript.

\section{References}

Ackerman, L., 2000, Identity is destiny: Leadership and the roots of value creation Berret-Koehler Publishers, San Fransisco, CA.

Bass, B.M., 1990, Handbook of leadership, The Free Press, New York.

Brewer, G.A., Selden, S.C. \& Facer, R.L., 2000, 'Individual conceptions of public service motivation', Public Administration Review 60, 254-264. http://dx.doi. org/10.1111/0033-3352.00085

Bryman, A., 2012, Social research methods, 4th edn., Oxford University Press, New York.

Bryman, A., Stephens, M. \& Campo, C., 1996, 'The importance of context: Qualitative research and the study of leadership', Leadership Quarterly 7, 353-370. http:// dx.doi.org/10.1016/S1048-9843(96)90025-9

Burden, J. \& Roodt, G., 2007, 'Grounded theory and its application in a recent study on organisational redesign: Some reflections and guidelines', SA Journal of Human organisational redesign: Some reflections and guidelines', SA Journal of Human
Resource Management 5(3), 11-18. http://dx.doi.org/10.4102/sajhrm.v5i3.147

Charmaz, K., 2006, 'Grounded theory: Objectivist and constructivist methods', in N.K. Denzin \& Y.S. Lincoln (eds.), Handbook of qualitative research, 2nd edn., 509-536, Sage, Thousand Oaks, CA.

Collins, J.C. \& Porras, J.I., 1996, 'Building your company's vision', Harvard Business Review 74(5), 65-77.

Conger, J., 2005, '360 and competency frameworks: Are we in the land of Oz?', paper presented at the Corporate Research Forum, London, 22th June.
Conger, J.A. \& Kanungo, R.N., 1998, Charismatic leadership in organisations, Sage, Thousand Oaks, CA.

Creswell, J.W., 2009, Research design: Qualitative, quantitative and mixed method approaches, 3rd edn., Sage, Los Angeles, CA.

Denison, D.R., 1990, Corporate culture and organisational effectiveness, Wiley, New York.'

Forbes, 2012, The 20 most powerful people in African business 2012, viewed 30 November2014,fromhttp://www.forbes.com/sites/mfonobongnsehe/2012/04/23/ the-20-most-powerful-people-in-african-business-2012/

Foreman, P. \& Whetten, D.A., 2002, 'Members' identification with multiple-identity organisations', Organisational Science 13(6), 618-635. http://dx.doi.org/10.1287/ orsc.13.6.618.493

Glaser, B.G., 1992, Basics of grounded theory analysis, Sociological Press, Mill Valley, CA.

Grobler, S.W., 2015, 'Requisite leader behavioural competencies for sustainable organisational performance', unpublished PhD dissertation, University of Pretoria, Pretoria.

Guba, E.G. \& Lincoln, Y.S., 1982, 'Epistemological and methodological bases of naturalistic inquiry', Educational Communication and Technology Journal 30(4), 233-252.

Guba, E.G. \& Lincoln, Y.S., 1998, 'Competing paradigms in qualitative research', in N.K Denzin \& Y.S. Lincoln (eds.), Handbook of qualitative research, 138-157, Sage, Thousand Oaks, CA.

Harris, L.C. \& Ogbonna, E., 1999, 'Developing a market orientated culture: A critical evaluation', Journal of Management Studies 36(2), 177-196. http://dx.doi. org/10.1111/1467-6486.00132

Hennessey, J.T., 1998, 'Reinventing government: Does leadership make the difference?', Public Administration Review 58(6), 522-532. http://dx.doi. org/10.2307/977579

Hollenbeck, G.P., McCall, M.W. \& Silzer, R.F., 2006, 'Leadership competency models: Theoretical and practitioner letters', The Leadership Quarterly 17, 398-413. http://dx.doi.org/10.1016/j.leaqua.2006.04.003

Howell, J.M. \& Avolio, B.J., 1993, 'Transformational leadership, transactional leadership, locus of control and support for innovation: Key predictors of consolidated business-unit performance', Journal of Applied Psychology 78, 891902. http://dx.doi.org/10.1037/0021-9010.78.6.891

Kotter, J.P. \& Heskett, J.L., 1992, Corporate culture and performance, The Free Press, New York.

Leedy, P.D. \& Ormrod, J.D., 2005, Practical research: Planning and design, 8th edn., Pearson, New Jersey.

Miller, L., Rankin, N. \& Neathey, F., 2001, Competency frameworks in UK organizations, CIPD, London.

Mouton, J., 2001, How to succeed in your Master's \& doctoral studies: A South African guide and resource book, Van Schaik Publishers, Pretoria.

Ogbonna, E. \& Harris, L.C., 2000, 'Leadership style, organisational culture and performance: Empirical evidence from UK companies', The International Journal of Human Resource Management 11, 766-788. http://dx.doi.org/10.1080/ 09585190050075114

Parry, K.W., 1998, 'Grounded theory and social process: A new direction for leadership research', The Leadership Quarterly 9(1), 85-105. http://dx.doi.org/10.1016/ S1048-9843(98)90043-1

Pfeffer, J., 1994, Competitive advantage through people: Unleashing the power of the work force, Harvard Business School Press, Boston, MA.

Rainey, H.G., 1997, 'Different public managements', in J.L. Brudney, J. Laurence, L.J. O'Toole \& H.G. Rainey (eds.), Advancing public management: New developments in theory, methods and practice, University Press, 253-260, Georgetown, Texas.

Rousseau, D.M. \& House, R.J., 1994, 'Meso organizational behavior: Avoiding three fundamental biases', Journal of Organizational Behavior 1, 13-31.

Schein, E.H., 1992, Organizational culture and leadership, 2nd edn., Jossey-Bass, San Francisco, CA.

Shah, S.K. \& Corley, K.G., 2006, 'Building better theory by bridging the quantitative/ qualitative divide', Journal of Management Studies 43(8), 1821-1835. http:// dx.doi.org/10.1111/j.1467-6486.2006.00662.x

Simon, C.A., 1998, 'Organizational performance in the public sector: A Comparison of 77 federal bureaus receiving or not receiving the president's Quality Award 1992-1997', PhD dissertation, United States International University

Strauss, A.L. \& Corbin, J.M., 1998, Basics of qualitative research: Techniques and procedures for developing grounded theory, 2 nd edn., Sage, London.

Swinburne, R., 1997, Simplicity as evidence for truth, Marquette University Press, Milwaukee, WI.

Wagner, J.A. \& Hollenbeck, J.R., 2010, Organizational behavior: Securing competitive advantage, Routledge, New York.

Yin, R.K., 2009, Case study research: Design and methods, 4th edn., Sage, Thousand Oaks, CA.

Yukl, G., 1998, Leadership in organizations, Prentice-Hall, Englewood Cliffs, NJ. 